\title{
Zeb Tortorici. Sins Against Nature. Sex and Archives in Colonial New Spain. Durham / Londres: Duke University Press, 2018, 327 pp.
}

\author{
Pablo Rodríguez Jiménez
}

$\mathrm{D}$ esde 1986, cuando Serge Gruzinski publicó su novedoso estudio “Las cenizas del deseo", no se publicaba una investigación histórica tan desafiante sobre la homosexualidad durante el periodo colonial novohispano. ${ }^{1}$ Es cierto que habían aparecido distintas investigaciones que ampliaban y enriquecían nuestra comprensión del campo de la sexualidad durante el periodo, especialmente porque analizaban muchas transgresiones a la doctrina establecida por la Iglesia. Sin embargo, conviene admitirlo, estas transgresiones tenían relación, casi siempre, con el matrimonio católico. Es decir, se trataba de relaciones heterosexuales prematrimoniales o al margen del matrimonio. Sins Against Nature, es bueno decirlo, no es sobre homosexualidad, pero es indiscutible que es uno de sus principales focos de atención.

Debemos reconocer que Zeb Tortorici, profesor de la Universidad de Columbia, es uno de los más dinámicos líderes de los estudios históricos coloniales sobre las marginalidades sexuales. Distintas publicaciones suyas confirman un desarrollo investigativo sostenido. ${ }^{2}$ En esta oportunidad nos presenta un estudio sobre casos de acusados de pecados contra natura sucedidos en México entre los siglos XVI e inicios del XIX. Para ello recorrió los archivos civiles y eclesiásticos de Ciudad de México y cerca de diez estados federados. También visitó archivos en Madrid y Sevilla, así como distintas bibliotecas de universidades americanas que albergan fondos documentales sobre la historia de México. El resultado fue un inventario de 327 expedientes sobre los pecados nefando, masturbación, bestialismo y solicitación. Por supuesto, la mayor parte versan sobre el siglo XVIII (174), después le siguen el siglo XIX (80), el siglo XVII (60) y el siglo XVI (13). La explicación

* Profesor Titular de la Universidad Nacional de Colombia.

1. Serge Gruzinski, "Las cenizas del deseo. Homosexuales novohispanos a mediados del siglo XVII", De la santidad a la perversión o de porqué no se cumplía la ley de Dios en la sociedad novohispana, ed. Sergio Ortega (México: Grijalbo, 1986) 255-283.

2. Zeb Tortorici, ed., Sexuality and the Unnatural in Colonial Latin America (Oakland: University of California Press, 2016). 
de estas distintas cifras tiene que ver con el crecimiento demográfico del país y el mayor control por parte de las autoridades.

El libro está conformado por sendos capítulos en los que de manera separada se analiza cada uno de los pecados contra natura nombrados. Su estudio combina la definición eclesiástica, tanto en sus aspectos teológicos y doctrinales, como en los disciplinares. También incorpora el tratamiento dado por la justicia civil. Ambas dimensiones son importantes en el estudio de los cambios y transformaciones que tuvieron los juicios para castigar estas contravenciones. Particularmente, en cuanto a una atenuación de las penas y castigos, fenómeno ocurrrido especialmente a partir del siglo XVIII bajo la influencia de la Ilustración.

Pocas veces los historiadores confian a sus lectores sus dudas metodológicas. Zeb Tortorici lo hace a conciencia, como una fórmula para proponernos una nueva perspectiva historiográfica. Luego de plantearnos su propósito inicial de realizar una historia social y cultural de la homosexualidad, prefiere considerar la posibilidad de adelantar una historia queer. Algo inédito para el contexto colonial hispanoamericano. Si por historia queer entendemos — según lo dice- una historia de lo indefinido, lo ambiguo, lo provisional y lo transicional, entonces su libro podría serlo. Pero Tortorici concluye que es tan solo un deseo, que una historia queer del periodo colonial es problemática, así la lleve en el corazón el investigador.

De alguna manera podríamos considerar que Sins Against Nature es una historia de los excesos sexuales en el México colonial. La riqueza de los casos que despliega no lo hace con el propósito de escandalizar sino de ilustrar todos los aspectos de las experiencias de los pecadores. El autor ha definido su vivencia con el término "visceral", como su represión y castigo. De hecho, era visceral la manera como eran cometidos, el manejo del cuerpo y el lenguaje utilizado. También era visceral la forma como las autoridades los calificaban y juzgaban. Valga como ejemplo nombrar el caso del cura Juan Vallejo Hermosillo, quien reconoció haber tenido relaciones sodomíticas con 115 hombres de distintos grupos étnicos y edades. Si eso no fuera ya un exceso y algo "visceral", también lo fue que realizara, durante su estadía en la cárcel, un listado en el que anotó sus nombres y el número de veces que tuvo sexo con ellos.

Una cuestión significativa que aborda se relaciona con la documentación y el archivo. De hecho, Tortorici considera el libro como un archivo que se ofrece al lector. Si bien se puede echar de menos un apéndice al final del libro con el listado total de los 327 casos localizados, el autor informa que este se puede consultar en el Faculty Digital Archive de la New York University. ${ }^{3}$ Se trata de un archivo que captura el deseo y la sexualidad. En él hay un sentido privilegiado que es la vista. Los denunciantes y los testigos de los pecados hablan de lo que vieron, tanto en los actos de masturbación, bestialismo, pecado nefando y solicitación. Lo visto es

3. Véase Zeb Tortorici, "Sins against Nature: Sex and Archives in Colonial New Spain (Archival Appendix)". https://archive.nyu.edu/handle/2451/42172. Adicionalmente, Tortorici asegura que más que un listado, contiene un verdadero archivo alimentado periódicamente con nueva información sobre los casos. 
la principal prueba en el levantamiento de las causas por los pecados cometidos. Con todo, Tortorici advierte que el archivo de los pecados contra natura estaba sometido a los prejuicios y valores culturales de los catalogadores y archivistas. Con reiterados ejemplos comenta su sorpresa al encontrar en los ficheros expedientes identificados con palabras que encubrían su verdadero contenido. Seguramente, por pudor, preferían llamar "malos tratos" o "tratos erróneos" a relaciones homosexuales.

Ciertamente, la vista era el sentido privilegiado de los testigos en los pecados de sodomía. Sus descripciones de los cuerpos, la desnudez, los miembros y los movimientos eran sustanciales. Pero también eran importantes las maneras como categorizaban el género de las parejas homosexuales. Según fuera la posición que ocupaba cada uno, arriba o abajo, se los identificaba como hombre o mujer. De los 327 documentos analizados en el libro, 129 corresponden a juicios contra personas acusadas de sodomía. Nuevamente la escasez de casos sobre lesbianismo, algo que lamenta Tortorici, puede provocar cierta decepción entre los lectores. Su explicación de que en la época las manifestaciones eróticas entre las mujeres pasaban inadvertidas y por eso no se denunciaban, es bastante razonable. Pero debemos reconocer que el caso de hermafroditismo analizado o las referencias a la mujeres "ahombradas" en algo mitigan la falta de tratamiento del sexo entre mujeres.

Tiene razón el autor al mostrar su extrañeza por la poca atención que se ha prestado al bestialismo en la historiografia mexicana. De hecho, comenta que en alguna ocasión que dio una conferencia sobre el tema durante un congreso en Tepoztlán, uno de los asistentes le preguntó por qué se ocupaba de ese asunto, que era algo que desacreditaba la cultura del país. Sins Against Nature analiza 144 casos de bestialismo, el relato de uno de ellos sirve de entrada al libro. El que sean casos ocurridos en zonas rurales más que urbanas, cometidos casi siempre por muchachos jóvenes, indígenas, mestizos o mulatos, no parecería sorprendernos. Lo que sí es un hecho, cuando menos inquietante, es que las penas para los acusados en el siglo XVI eran la castración y, en ocasiones, la muerte. Siglos después, la justicia dejó de ocuparse de esta desviación y la relegó al ámbito privado.

El pecado de solicitación, es decir, el abuso del confesionario con fines de deleite sexual, dada su gravedad, era perseguido por la Inquisición. Este tema ha recibido alguna atención de parte de los historiadores, especialmente como una contravención heterosexual. Tal vez, debido a ello, el autor prefirió analizar los casos de curas con conductas homosexuales que tuvieron la cautela de respetar los confesionarios y las sacristías. Sus relaciones con jovencitos ocurrían en otros espacios de las iglesias o en sus casas de residencia. Acá de nuevo la definición de "visceral" tiene todo el sentido, no solo en cuanto a la descripción cruda de su sexualidad, sino a la exposición escandalosa que los curas llegaban a mostrar. Como los hechos no habían irrespetado el carácter sagrado del confesionario, debían ser tratados por la justicia eclesiástica. Esta justicia prestaba poca atención a las denuncias de los feligreses y, cuando lo hacía, terminaba aplicando penas bastante leves a sus díscolos ministros. Igualmente, el autor ha querido tratar en 
este libro un aspecto muy poco analizado por la historiografia colonial. Evidentemente, la masturbación y la polución hacen parte de los pecados contra natura, toda vez que es un derramamiento seminal que no conduce a la reproducción. Un importante número de casos inquisitoriales, estudiados en sus aspectos heréticos, contienen manifestaciones de un deseo divino que no ha sido tomado en cuenta. Hombres y mujeres, no siempre miembros de órdenes religiosas, llegaban a tener manifestaciones eróticas y sexuales hacia las imágenes religiosas de las iglesias o de sus casas que eran absolutamente delirantes. Besos, tocamientos y masturbación hasta el orgasmo eran algunas de sus manifestaciones. Pero en otros momentos, eran visiones en las que mujeres se sentían penetradas por Jesús. En fin, es algo que podríamos considerar como una experiencia extrema y extraordinaria de la religiosidad barroca.

Sins Against Nature termina con un capítulo inesperado y novedoso. Se trata de la explicación del origen del diseño del Archivo General de la Nación de México. Su modelo corresponde a un panóptico con el nombre de Lecumberri. Con un conjunto de fotografias tomadas por el propio Zeb Tortorici, nos narra su experiencia de investigador de los pecados contra natura en un archivo que conserva toda la estructura de una cárcel. Mientras observaba el movimiento de los documentos de un espacio a otro, casi siempre en los que antiguamente eran celdas, pensaba que los procesados y castigados de hace varios siglos, por su placer desviado de las normas, continuaban encerrados en una cárcel.

DOI: 10.17533/udea.trahs.n17a10 